\title{
THE INFLUENCE OF THE OPERATIONAL ENVIRONMENT ON THE PROCESS OF PLANNING MILITARY ACTIONS
}

\author{
Constantin GRIGORAŞ \\ "Nicolae Bălcescu” Land Forces Academy, Sibiu, Romania \\ grig_costel67@yahoo.ro
}

\begin{abstract}
The international security environment is constantly changing. Ensuring the success of the fight against the new threats can be achieved by understanding the operational environment that is becoming increasingly more complex in the context of the profound changes in the political, social and economic environment of the past decade and of the advanced technologies that create new challenges for all forces with responsibilities in the field of national defense and security, regional and global. The trends in the current operational environment, based on the analysis of the conflicts of the last decades, lead to a new approach to the development of military capabilities, the process of planning, organizing and conducting military actions, the ways of achieving victory in the new conditions imposed by the realities of the battlefield.
\end{abstract}

\section{Keywords: operational environment, planning, military operations, hybrid war}

\section{Introduction}

The evolution of the international security environment presents a complex range of threats, challenges and opportunities, which makes it possible for military forces to be called upon to act in a wide variety of conditions. At the same time, innovation and technology remodel this environment, multiplying and developing the goals that can be achieved by even the minor actors.

Many factors combine to define the future operational environment. The army must be adapted to the probable conditions that will be found in the complex operational environment. The future is uncertain, but not entirely unknown. It will remain complicated, volatile and dangerous.

The transformation of the war has inevitably kept pace with the trends of human society evolution, the emerging advanced technologies radically changing the means and modalities of military action, the contemporary forms of confrontation (political, economic, cultural, religious etc.) moving the epicenter of modern conflicts from the strict military field to the geopolitical and geo-economic one.

The new technologies have the potential to influence or modify not only the tactics, the operative art or the military strategy, but also the political goals of developing a state, the evolution of its interests and its role on the world arena, with the aim of positioning it so as to obtain decisive, regional or even global influence.

In order to achieve an effective preparation of the military actions in response to the challenges at the beginning of the millennium, it is necessary that the fundamental nature of planning and plans should be analyzed in depth. Therefore, the planner must have a multilateral understanding of the goals of the operational environment and of the characteristics of the planning process, as 
well as of the object and traits of the final products of the planning.

\section{Planning of the military action - conceptual delimitations}

The preparation of the operation includes all the activities and measures performed in order to create the conditions necessary for the execution of the operation, from the time of receipt (the specifics of the mission) until the start of the operation. For the preparation of a military action, commandments, through the structures of their composition, plan the military action, organize and coordinate the actions of the subordinate forces, and execute the control of the action plan's implementation by the subordinate command structures.

The nature of modern warfare requires planning and conducting the combat in all environments, in a unique leadership and coordination system. In the military leadership, the main aspects of planning are the relative stability of the plans and the early preparation of the solutions to be adopted in the event of emergence of some disturbing factors. As leadership tools, plans need to be rigorously respected, but also adapted to the new conditions. Even the repeated changes in planning lead to the instability of plans, diminishing the time at the disposal of commandments, and removing them from the proper leadership.

Regardless of the type of military actions, planning is a coordinated process of the command structure for determining the best way to accomplish a mission. Planning must support the adaptation of the military structure to the requirements of the confrontational environment. In principle, there are two ways through which we can adapt to the dynamics of reality.

The first method is to anticipate the requirements imposed by the future evolution of the situation and the preparation for solving them before the action begins. Anticipation allows us to adapt in a methodical and systemic manner, using all the resources at our disposal.
However, given the uncertainty that characterizes war and conflict in general, it is almost impossible to predict how all the actions taken will be carried out. Consequently, we must be able to quickly adapt ourselves to the new situations.

The second adaptation method, called improvisation, is the ability to carry out actions that were not originally planned, which require changes to the plans in order to cope with the unforeseen circumstances. These two adaptation methods are complementary, the difference between them being given only by the time available to prepare the action.

Both ways of adapting to the battlefield situations are based on planning, this being the main means by which we can anticipate the different demands of combat actions and we can prepare to cope with them. Thus, we can refer to planning as being anticipated adaptation. Planning also allows for adaptation during execution, because even when we perform an action that has not been planned, we rarely do it without any training. As a rule, the previously prepared plan is adjusted on the basis of the understanding of the situation, the mission received and the expected outcome.

Any operational environment, from the real world or from the training environment, can be analyzed in terms of eight operational variables. While these variables may have some value in describing the operational environment (globally), their importance increases when they are used to define a specific operational environment. Each of these "conditions, circumstances and influences" and their possible combinations will vary depending on the situation. These variables are interdependent and, in some cases, they overlap.

The operational variables describe not only the military aspects of an operational environment, but also the influence of the population on it. Military planners analyze the operational environment using six interdependent operational variables (PMESII): the political variable, the 
military variable, the economic variable, the social variable, the informational variable and the infrastructure variable. To these variables two more can be added: the environment and time.

Certain variables will have a greater or lesser importance depending on the situation. By studying and understanding these variables, by integrating them into training, we can succeed in preventing the opponent from using them against the friendly groups of forces or from finding ways to use them for their own advantage.

At a strategic level, we have three basic types of planning:

- based on risks and threats in the security environment (fixed framework);

- founded on its own military capabilities (flexible framework);

- based on countering the risks in the security environment and its own vulnerabilities (extended flexible framework). The latter model is generally used by the armies of other NATO member countries, particularly by the USA. This need to reorient the foundation of strategic planning and, implicitly, rethinking the structure of forces has come about as a result of the reality that not only are the states potentially aggressive but also increasingly the non-state entities. Unlike states, the terrorist groups and organized crime have a cross-border nature, many of them acting globally, without any regard to rules, norms, limitations or constraints of an ethical or moral nature, or pertaining to international law.

At a strategic level, this planning model has as its main purpose not the identification of enemies, but of the phenomena that can lead to a destabilization of the international order or which, when not counteracted, can endanger the stability and security of some states, areas or regions.

The threats and risks in the current security environment are identified, listed, and specified in various strategies by military analysts and planners. They are found in various official documents, in the long-term strategic visions, the national security strategies, and/or the military strategies or doctrines.

In addition, the adoption of the Strategic Planning System, based on the analysis of the risks in the security environment and internal vulnerabilities - and, implicitly, on a structure of forces designed on this basis, has several advantages, such as: providing a flexible framework and a great freedom of thinking for the military planners; the scenarios built within the strategic planning cover the entire range of identified risks, providing for the necessary countermeasures.

As a result, the structure of forces designed for these missions, and especially within collective defense, will be flexible, modular, maneuverable, equipped and trained according to the NATO standards.

The ability to quickly design forces significantly contributes to preventing, deterring or stopping potential belligerents, as well as the conflict itself.

In fact, the fulfillment of the above mentioned functions, but especially the conflict prevention, are the main advantages and at the same time characteristics of the type of planning based on the counteracting of the risks and threats of the security environment and of their own vulnerabilities.

Given the generally low level of forces and of limited resources, the ability to work closely within the Alliance is of utmost importance. The defense arrangements of the alliance for the defense of the national territory, where the integrated military structure plays a key role, are essential in this respect.

Today, social segments, multinational organizations, civil society and media structures are also involved in the configuration of the operational environment. As a result, the planning of military actions must also take into account elements which in the past were irrelevant or not taken into account for reasons of profitability, namely: reducing unnecessary 
losses to the opponent and eliminating own losses; protecting the opponent's economic, social, cultural objectives; protection of their own forces; the need for post-conflict stabilization of the confrontation environment; taking into account the reaction of domestic and international public opinion; estimation of post-conflict economic developments; the impact of information domination on the battlefield; concentrating the influences of the operation on the enemy and not the actual influence.

The military action has always been subject to profound transformations expressed by the effects of mutations in international relations and, implicitly, by the complex evolution of the operational environment.

\section{The operational environment - fundamental element of analysis for planning military operations}

The characteristics of the operational environment after the end of the Cold War have led to a situation that can be synthesized as a confrontation for a new world order, which has the following characteristics: the attempt made by the great states to increase their influence, the struggle for regaining the independence of the small states, which have been forcibly absorbed into strong state structures; the idea built on the basis of "the USA right to wield preemptive wars" [1] anywhere in the world when their security is threatened.

The operational environment can be understood only in strict interdependence with the international system developed during the Cold War, whose direct consequences we feel.

Both the events and trends that currently take place point to a progressive enhancement of the changes and a diminution of discontinuity elements. Against this background, the two events (1990 and September 11, 2001) decisively marked the current configuration of the operational environment.

The operational environment was reassessed by introducing the notion of international terrorism into the common language, although terrorism and crossborder cooperation between terrorist structures had existed, the magnitude being given by the events of September 11, 2001, and later by those in Spain, Great Britain, Turkey and France. These events have developed the concept of operational environment having a variable geometry. Characteristic of the current operational environment is "the absence of the danger of a major conflict between the main powers of the world and the further emergence of a new generation of combatants, sub-state entities, non-national groups whose identity is founded on a common basis, such as ideology, tribal affiliation, culture, religion, illegal economic activities, or a combination of some or all of these factors" [2].

Globalization, the phenomenon of transparency and the permeability of borders will increase the scale of the operational environment, allowing for the regional instability to spread very easily. In this context, we expect the operational environment to no longer be a conventional one, but to be shared by a broad and growing range of actors capable of using force and violence in diverse ways.

The operational environment analysis should extend beyond the geographical area of the conflict. The operational environment includes components that cover all the environments in which military actions can take place: the physical environment, the informational environment and the moral environment.

The physical environment is made up of the physical entities and areas, the actions and the effects that manifest in the operational environment. It includes the military forces, the armed groups, the civilian population, the natural resources, the infrastructure, and the geographical space (terrestrial, air and maritime) and meteorology (climate, weather) as well.

The informational environment illustrates the environment of all actions and 
processes involving the procurement, processing and use of information. Information is the bridge between the physical environment and the moral environment, the integrating element of all the actions carried out in order to achieve the objectives pursued. The informational environment is the space for the expression of all forms of divergence based on information. Important components of the information environment are the electromagnetic environment and the cybernetic environment.

The moral environment includes the attitudes, beliefs and determinations specific to individuals or groups of individuals, manifested through their "will" to overcome fear and aversion and to achieve the unity of effort necessary to accomplish the goals/objectives proposed. The moral environment includes two basic components: the psychological component and the cognitive component.

The important feature of the current operational environment is the development of solutions for the security complex that highlights the existence of a significant interconnection between participants at a military, diplomatic, political, economic, social or environmental issues level. The security complex can be seen, from this perspective, "as a result of regionalism but also a correlated element" [3]. These international circumstances call for new rules, raising practical and conceptual issues in the setting up of the current operational environment, from manifesting interest at all levels to punctual or unilateral approaches.

From another point of view, the globalization manifested through the amplification of interconnections between countries has created interdependence between the internal and external risks so that they can influence each other, which implies an upward improvement in the configuration of the operational environment through crisis management measures and the exchange of information between the actors involved that should take place in real time.

The main feature of the current operational environment is the space where the confrontation can be initiated. From this perspective, the contemporary operational environment represents a sum of conditions, circumstances and influences that affect the projection and use of the structures of forces and which require political-military level decisions.

Although the conflicts of the last years were asymmetrical or dissymmetric with elements belonging to the hybrid war, the possibility of major combat operations in the future is not to be disregarded. As is also stated in the international specialized literature, the hypothetical opponent of future conflicts will continue to be one that uses irregular forces, ranging from welltrained insurgents with great fighting experience whose aim is to change local government or achieve some religious desiderata to criminal or tribal groups seeking to maintain control in certain areas in order to achieve their economic goals.

Regardless of the goal pursued, the opponent in the future operational environment will be highly adaptable and fluid, being able to use a wide range of technological means, equipment and procedures, combined with conventional weapons and improvised means.

The British doctrine pragmatically highlights the character of future military conflicts: "The conflict of the future will not be an exact science: it will remain a unique human activity, impossible to foresee with precision. The adversaries (state or nonstate) and threats (conventional and unconventional) will be in a mixed configuration. The palette of threats will expand, including the proliferation of weapons of mass destruction, cyber-attacks and other new irregular threats" [4].

However, there are some "constants" that define, in general, the nature of the operational environment. In this respect, we can mention: globalization, as the main 
phenomenon that acts on the security environment, creating both development opportunities and new risks and threats; the persistence or the intensification of tensions (old ethnic or religious disputes - especially the case of Kosovo), as well as increasing cross-border crime; the availability, on world markets, of advanced technologies for a wide variety of national states or for non-state actors; the integration of the military intervention into a complex set of diplomatic, informational, economic and other type of actions for the defense of national interests; the modernization of the armed forces, even under the constraints of their own national economies. In conclusion, one of the "constants" is that there are a lot of "variables". These "variables" of the contemporary operational environment will determine the existence of a defined number of operational environments that may occur under certain circumstances or scenarios.

"Globalization is a process of interaction and integration of the populations, companies and governments of the different nations, a process conducted through treaties, investments and access to technological information. This process has effects on the environment, culture, political and economic system, development and prosperity, development and social psychological state of the whole world" [5]. The operational environment will continue to evolve, presenting to the military forces various challenges in the form of threats generated by opponents who carry out actions ranging from conventional to unconventional, with the capabilities of state-of-the-art weapons and technology. These significant challenges arise from: population growth, the migration phenomenon, resource depletion, climate change, continued globalization and technological advance. A combination of these factors could lead to major challenges, as well as to instability of the security environment

The population growth is likely and will generate overcrowding, especially in the urban areas, and this will lead to instability. The population is estimated to reach 8 billion in 2024, 9 billion in 2040, and 10 billion in 2062 [6].

Decreasing resources will lead to increased costs associated with them, which combined with population growth can lead to very large inequalities between nations or even within them.

Climate change is topical. Seasons and precipitations are changing, temperatures are rising, glaciers are melting, and the average global sea levels are rising.

Urbanization has become today a general, specific and irreversible phenomenon, with a marked evolution towards complexity, scale and dynamism.

Technology is the amount of knowledge that applies science to achieving the goals. The technological advance can lead to an increase of the economic imbalance among state actors, generate regional instability, but can also provide opportunities for controlling future threats. The technological developments will provide opportunities for the armed forces to gain a military advantage in a future armed conflict, as well as a pressure on defense budgets to counteract the adverse capabilities.

Technology development is expected to be steadily rising, moving to new directions and at much higher speeds, which will make it difficult to maintain the processes of combat technique procurement for defense technology to meet new requirements. The acquisition of superior technology will not be enough; more important and more successful will be the one who will be able to integrate the new technologies, i.e. to modernize its operational concepts, the process of planning the military operations and to upgrade its existing systems.

The nuclear weapons made the distinction between usable and unusable power, being a paradox of the nuclear age, in the sense that, in contrast to the experience of any previous epoch, the rise of military power 
has not determined the increase in political power. A concrete picture of the process of global transformation of armaments and military capabilities has been highlighted since the 1991 Gulf War, where the advances in technology integration have been reaped with surprisingly large effects, thus creating the prerequisite for any national military procurement program worldwide.

In conclusion, I appreciate that the analysis of the operational environment is one of the basic activities in the battle planning process. The growing degree of global interactions will strongly influence the future threats. The access to the advanced technologies, together with the possibility of possession and use of weapons of mass destruction, will increase the number of "actors" with a military potential high enough to change the regional power balances.

It is essential to understand these general trends as they help the decision-making element to implement coordinated actions at national level in response to these changes. The global trends could lead to tensions, instability and even conflicts. Regardless of the goal pursued, the opponent in the future operational environment will be highly adaptable, being able to use a wide range of technological means, equipment and procedures, combined with conventional weapons and improvised means.

In the future, the national military forces or the Alliance forces will continue to work in an increasingly more complex environment, which will pose increasingly more diverse and unexpected challenges. Therefore, it is necessary to formulate forecasts and opinions on the configuration of the operational environment of the future and on the threats that may arise in this context. These projections of future conflicts allow military planners to better understand the context in which forces will operate and establish clear directions and concepts for the development of the military capabilities of the armed forces of the future.

\section{References}

[1] Francis Fukuyama, America la răscruce, Antet Publishing House, Bucharest, 2006, p.83.

[2] Teodor Frunzeti, Gestionarea crizelor în războiul rece, in Lumea Militară no.1/2006, p.30.

[3] Luciana Alexandra Ghica, Marian Zulean, Politica de securitate naţională, Polirom Publishing House, Iaşi, 2007, p.109.

[4] Strategic trends program. Future character of conflict, UK Ministry of Defence, 02.02.2010, p. 6 from https://www.gov.uk/government/publications/future-character-ofconflict, accessed on 12.04.2015.

[5] http://www.globalization101.org/what-is-globalization/ accessed on 27.03.2017

[6] https://www.ined.fr/en/everything_about_population/graphs-maps/population_graphs/ accessed on 26.03.2016 